American Journal of Pharmaceutical Education 2017; 81 (1) Article 5.

\title{
RESEARCH
}

\section{Evaluating the Effectiveness of an Educational Intervention to Improve the Patient Safety Attitudes of Intern Pharmacists}

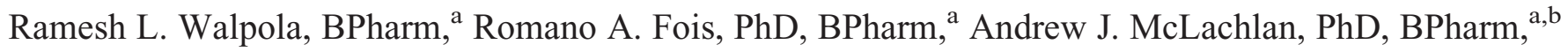 \\ Timothy F. Chen, PhD, BPharm, DipHPharm ${ }^{\mathrm{a}}$ \\ a The University of Sydney, New South Wales, Australia \\ ${ }^{\mathrm{b}}$ Centre for Education and Research on Ageing, Concord Repatriation General Hospital, Concord, NSW, Australia \\ Submitted September 9, 2015; accepted November 11, 2015; published February 25, 2017.
}

\begin{abstract}
Objective. To evaluate the effectiveness of a face-to-face educational intervention in improving the patient safety attitudes of intern pharmacists.

Methods. A patient safety education program was delivered to intern pharmacists undertaking The University of Sydney Intern Training Program in 2014. Their patient safety attitudes were evaluated immediately prior to, immediately after, and three-months post-intervention. Underlying attitudinal factors were identified using exploratory factor analysis. Changes in factor scores were examined using analysis of variance.

Results. Of the 120 interns enrolled, 95 (78.7\%) completed all three surveys. Four underlying attitudinal factors were identified: attitudes towards addressing errors, questioning behaviors, blaming individuals, and reporting errors. Improvements in all attitudinal factors were evident immediately after the intervention. However, only improvements in attitudes towards blaming individuals involved in errors were sustained at three months post-intervention.

Conclusion. The educational intervention was associated with short-term improvements in pharmacist interns' patient safety attitudes. However, other factors likely influenced their attitudes in the longer term.
\end{abstract}

Keywords: patient safety, education, pharmacy, attitude, questionnaire, graduate

\section{INTRODUCTION}

Since the publication of the seminal reports To Err is Human and An Organisation with a Memory, the improvement of patient safety has received greater attention across all health systems and disciplines. ${ }^{1,2}$ Consequently, a paradigm shift in the management of patient safety incidents has occurred, from the traditional strategies centered on blaming and shaming the individuals involved to adopting a systems-based approach, evaluating the different factors that resulted in the incident occurring. ${ }^{3}$ To drive this change, a number of global initiatives to improve safety have been established. ${ }^{4}$ Education and professional development early in the careers of health care professionals was identified as a key initiative in driving generational paradigm change. ${ }^{5-8}$ In November 2011, the World Health Organisation released a multiprofessional edition of The Patient Safety Curriculum Guide. ${ }^{9}$ This comprehensive guide was designed to

Corresponding Author: Ramesh Walpola, Faculty of Pharmacy, Bank Building (A15), The University of Sydney, New South Wales, Australia 2006. Tel: +61 2-9036-7081.

E-mail: ramesh.walpola@sydney.edu.au address many of the capacity and capability issues institutions may have in providing patient-safety focused training. Globally, many pharmacy schools are progressively introducing more patient safety training to students. ${ }^{10}$ The majority of the training is generally contained in the more senior years of professional degree programs, with some programs gradually shifting some of the training to formative years to have a greater impact in creating positive patient safety attitudes and behaviors. ${ }^{11}$ However, this approach alone may be insufficient in ensuring positive patient safety practices by practitioners who have recently graduated. ${ }^{12}$

Under the current pharmacy internship model in Australia, graduates must complete 1,824 hours of supervised practice in combination with an approved intern training program after the completion of either a bachelor or master of pharmacy program prior to registration as a pharmacist. ${ }^{13,14}$ Supervised practice must be completed in an approved setting, with the majority of interns completing their hours in community pharmacy practice and a smaller proportion working in hospital settings. At the commencement of their internships, students transition into clinical roles, increasing their rate of socialization 


\section{American Journal of Pharmaceutical Education 2017; 81 (1) Article 5.}

into the profession (the process through which interns acquire the values, attitudes, skills, and knowledge relating to the way in which they practice). Studies highlight that the key positive influences on new graduates' professional socialization include education programs, practice environments, and quality role models from both educational and practice settings. ${ }^{15-18}$ Interns working in environments with suboptimal practice may be influenced to develop poor practices, which have the potential to place the safety of their patients at risk. Therefore, it is important that pharmacy intern training programs have the capability to foster good practices among interns and enable interns to identify poor practices.

All Australian pharmacy intern training programs contain self-directed and reflective tasks for interns to develop a practical understanding of the causes of dispensing errors as well as patient and medication safety incidents. However, to date, no program has included specific face-to-face teaching in patient or medication safety. Studies in other health care disciplines highlight that patient safety knowledge, skills, and attitudes can improve through the provision of face-to-face patient safety education that is integrated into graduate training programs. ${ }^{6,8,19,20}$ Therefore, this study aimed to evaluate the effectiveness of a tailored patient safety educational intervention in improving the patient safety attitudes of intern pharmacists, and to specifically understand the intervention's effect on the manner in which interns may respond to patient safety issues.

\section{METHODS}

A repeat cross-sectional study design was employed, with intern pharmacists enrolled in the Intern Training Program at The University of Sydney surveyed on their patient safety attitudes immediately prior to, immediately after, and three months after the intervention. Data were collected between February 2, 2014 and May 3, 2014, with ethical approval to conduct this study granted by the Human Research Ethics Committee at The University of Sydney.

A tailored patient safety education program was developed for intern pharmacists enrolled in The University of Sydney Intern Training Program in 2014, with the core focus of enhancing intern pharmacists' patient safety skills and knowledge. The program was integrated into the first of four face-to-face workshop blocks of the year. The program consisted of two elements. First, an 80minute plenary session was delivered to reintroduce a number of patient safety concepts including: effect of harm, teamwork, communication skills, managing clinical risk, human factors, and medication safety issues. This was followed by participation in a 100-minute small group workshop session with approximately 10 interns, led by a practicing pharmacist who had received prior training in delivering the patient safety workshop. The workshop session was designed to enable interns to relate to the concepts that had been discussed earlier in the plenary session. As part of the workshop, the interns were guided through three scenarios: a complex community-based scenario which applied a root cause analysis approach to the solution; a complex hospital-based scenario, designed to highlight hospital-specific problems; and a patient-centered scenario to highlight medication safety issues from a patient's perspective. As part of each scenario, interns were asked to identify the contributing factors for each incident and to think about how each of the incidents could have been prevented and their own role in ameliorating potential safety issues.

The survey tool used to evaluate the intervention was adapted from the Patient Safety/Medical Fallibility Curriculum Survey developed by Madigosky and colleagues, ${ }^{21}$ which has been previously validated for use with pharmacy students. ${ }^{22}$ The survey comprised two parts: the first part contained 18 of the original 23 attitudinal items of the previously validated survey, with five items that related to current university education being excluded; the second section collected demographic details including gender, age, workplace (internship site), prior health care experience, and involvement with an incident that resulted in harm or potential harm as a result of receiving health care. A 5-point Likert-type scale was used to measure student attitudes, with possible responses ranging from strongly disagree to strongly agree.

All data analyses were completed using IBM SPSS Statistics, version 21 (SPSS Inc., Chicago, IL). Each participant's student number was used to match responses between time points. Descriptive statistics were used to summarize participant characteristics and their practice history. The relationships between each of the participant demographic characteristics and their effects on survey responses were evaluated using Kruskal-Wallis tests. A Bonferroni correction was applied to account for multiple comparisons, reducing the $p$ value for significance to .001 .

An exploratory factor analysis (EFA) was performed on baseline survey responses to understand the latent structure underpinning intern pharmacists' responses to the survey, with maximum likelihood estimation and varimax rotation being used. Kaiser's criterion for factor retention was adopted, with individual factor loadings greater than .32 considered significant for retention. ${ }^{23,24}$ The factor structure was assessed for a theoretical basis, with an examination of the scree plot used to verify the number of factors retained. 


\section{American Journal of Pharmaceutical Education 2017; 81 (1) Article 5.}

Using the factor structure identified from the EFA, weighted sum factor-based scores were calculated for all factors at each time point. ${ }^{25}$ Based on the current recommendations for the analysis of Likert-type scale data, ${ }^{26}$ survey responses were analyzed using parametric tests. Participants with missing data were excluded from the analysis. Repeated measures analysis of variance (ANOVA) was used to evaluate changes to interns' patient safety attitudes on each of the measured factors, as the assumption of sphericity was met. Post-hoc analyses with paired $t$ tests were also performed to evaluate further the significance of the attitudinal changes, again adjusting for multiple comparisons with a Bonferroni correction.

\section{RESULTS}

Of the 120 interns enrolled in the program, 115 (94.3\%) completed the surveys prior to and immediately after the educational intervention and 95 (78.7\%) interns fully completed the survey at three months. The characteristics of the intern pharmacists at the time of the intervention (described as baseline, incorporating prior to and immediately after) and three months later are summarized in Table 1 . The majority of interns were working in community pharmacies $(79.1 \%$ at baseline $/ 80.2 \%$ at three months), while a minority of interns were working in hospital settings $(16.5 \%$ at baseline $/ 16.7 \%$ at three months). Notably, the number of interns who had been involved in or witnessed an incident that resulted in harm to a patient increased significantly ( 55 vs $59, p=.05$ ). Demographic characteristics did not influence interns' responses to any of the survey items after accounting for multiple comparisons with a Bonferroni correction.

Exploratory factor analysis was performed on the survey responses of the 115 interns who completed the survey at baseline. A four factor solution (Table 2) with $55.1 \%$ total variance explained was achieved. A total of four items were removed from the analysis due to low communalities (less than 0.2) or low factor loading (less than 0.32$){ }^{23}$ The four factors were labeled as being (1) attitude towards addressing errors; (2) the acceptability of questioning more senior health care professionals' behaviors; (3) attitude towards blaming an individual involved in the error; and (4) attitude towards the reporting of errors.

A one-way repeated measures ANOVA was conducted to evaluate the effect of the patient safety educational intervention on intern pharmacists' patient safety attitudes using data from 95 participants who fully completed the survey at all three time points (Table 3 ). The ANOVA demonstrated that there was a significant change in all four attitudinal factors measured: addressing errors $\mathrm{F}(2,188)=7.99 p<0.001$; questioning behaviors, $\mathrm{F}(2,188)=6.11, p=0.003$; blaming the individual, $\mathrm{F}(2,188)=12.17, p<0.001$; and reporting errors, $\mathrm{F}$ $(2,188)=8.43, p<0.001$.

Paired $t$ tests were used to evaluate the magnitude of effect that the intervention had on the attitudes of participants immediately after and three months after the intervention. A significant improvement in all four attitudinal factors was observed immediately after the intervention: addressing errors $t(94)=4.30, p<.001$; questioning behaviors, $t(94)=3.57, p=.001$; blaming the individual, $t(94)=-4.87, p<.001$; and reporting errors, $t(94)=4.58, p<.001$. However, when interns were surveyed three months after the intervention, only their attitudes towards blaming individuals had sustained improvement, $t(94)=3.12, p=.002$ (Table 3). Interns' scores related to their attitudes towards: addressing errors $(t(94)=0.92, p=.36)$, questioning behaviors $(t(94)=1.96$,

Table 1. Participant Characteristics at Baseline and Three Months After the Education Program

\begin{tabular}{|c|c|c|c|}
\hline Characteristic & Baseline $^{a}(n=115)$ & Three Months (n=96) & $P$ value \\
\hline \multicolumn{4}{|l|}{ Gender } \\
\hline Male, $\mathrm{n}(\%)^{\mathrm{b}}$ & $35(30.4)$ & $28(29.2)$ & \\
\hline Female, $\mathrm{n}(\%)^{\mathrm{b}}$ & $80(69.6)$ & $68(70.8)$ & 0.16 \\
\hline Age, in years, mean (SD) & $23.7(3.6)$ & $24.0(3.7)$ & $>0.001$ \\
\hline \multicolumn{4}{|l|}{ Place of Practice } \\
\hline Not Working, $\mathrm{n}(\%)^{\mathrm{b}}$ & $4(3.5)$ & $2(2.1)$ & \\
\hline Community, $\mathrm{n}(\%)^{\mathrm{b}}$ & $91(79.1)$ & $77(80.2)$ & \\
\hline Hospital, n $(\%)^{\mathrm{b}}$ & $19(16.5)$ & $16(16.7)$ & \\
\hline Industry, $\mathrm{n}(\%)^{\mathrm{b}}$ & $1(0.9)$ & $1(1.0)$ & 0.26 \\
\hline Months worked in pharmacy, mean (SD) & $26.83(21.5)$ & $29.02(23.0)$ & 0.02 \\
\hline $\begin{array}{l}\text { Students who have been involved in or } \\
\text { witnessed harm while working, } \mathrm{n}(\%)^{\mathrm{b}}\end{array}$ & $55(47.8)$ & $59(61.5)$ & 0.05 \\
\hline Students who have witnessed harm to a loved one, $\mathrm{n}(\%)^{\mathrm{b}}$ & $28(24.4)$ & $32(33.3)$ & 0.11 \\
\hline
\end{tabular}

${ }^{a}$ Baseline scores incorporate responses immediately prior to the program (T1) and after the program (T2)

${ }^{b}$ Percentages based on denominator of number of valid responses only 


\section{American Journal of Pharmaceutical Education 2017; 81 (1) Article 5.}

Table 2. Exploratory Factor Analysis (EFA) Rotated Factor Structure of Participant Responses Prior to the Program

\begin{tabular}{|c|c|c|c|c|}
\hline \multirow[b]{2}{*}{ Item } & \multicolumn{4}{|c|}{ Exploratory Factor Analysis Constructs } \\
\hline & $\begin{array}{l}1 \text { Addressing } \\
\text { Errors }(\alpha=0.71)\end{array}$ & $\begin{array}{c}2 \text { Questioning } \\
\text { Behaviors }(\alpha=0.81)\end{array}$ & $\begin{array}{c}3 \text { Blaming the } \\
\text { Individual }(\alpha=0.55)\end{array}$ & $\begin{array}{c}4 \text { Reporting } \\
\text { Errors }(\alpha=0.47)\end{array}$ \\
\hline $\begin{array}{l}\text { If there is no harm to a patient, there is } \\
\text { no need to address an error. }\end{array}$ & 0.73 & & & \\
\hline $\begin{array}{l}\text { If I saw an error that DID NOT cause harm, } \\
\text { I would keep it to myself. }\end{array}$ & 0.65 & & & \\
\hline $\begin{array}{l}\text { If I saw an error that DID cause harm, } \\
\text { I would keep it to myself. }\end{array}$ & 0.63 & & & \\
\hline $\begin{array}{l}\text { Learning how to improve patient safety } \\
\text { is an appropriate use of time in } \\
\text { pharmacy programs at university. }\end{array}$ & 0.54 & & & \\
\hline $\begin{array}{l}\text { Many errors are due to things } \\
\text { that health care professionals } \\
\text { can't do anything about. }\end{array}$ & 0.33 & & & \\
\hline $\begin{array}{l}\text { It is acceptable for an intern } \\
\text { pharmacist to question the } \\
\text { actions of a registered pharmacist. }\end{array}$ & & 0.98 & & \\
\hline $\begin{array}{l}\text { It is acceptable for a pharmacist to } \\
\text { question the decisions of a } \\
\text { prescriber (such as a doctor } \\
\text { or nurse practitioner). }\end{array}$ & & 0.68 & & \\
\hline $\begin{array}{l}\text { Disciplinary action against } \\
\text { an individual who made } \\
\text { an error is an effective method } \\
\text { of preventing future errors. }\end{array}$ & & & 0.74 & \\
\hline $\begin{array}{l}\text { After an error occurs, an } \\
\text { effective strategy is to work } \\
\text { hard to be more careful. }\end{array}$ & & & 0.41 & \\
\hline $\begin{array}{l}\text { Effective responses to errors in the delivery } \\
\text { of health care focus primarily } \\
\text { on the health care professional involved. }\end{array}$ & & & 0.38 & \\
\hline $\begin{array}{l}\text { Competent health care professionals } \\
\text { do not make errors that } \\
\text { lead to patient harm. }\end{array}$ & & & 0.37 & \\
\hline $\begin{array}{l}\text { Pharmacists should report errors } \\
\text { to an affected patient if harm to } \\
\text { the patient has occurred. }\end{array}$ & & & & 0.64 \\
\hline $\begin{array}{l}\text { Pharmacists should discuss and } \\
\text { report errors to an affected } \\
\text { patient even if the patient } \\
\text { is NOT harmed. }\end{array}$ & & & & 0.49 \\
\hline $\begin{array}{l}\text { Only medical practitioners } \\
\text { can determine the causes } \\
\text { of a medical error. }\end{array}$ & & & & 0.38 \\
\hline
\end{tabular}

NB: Blank cells contain factor loading less than 0.32

$p=.053)$, and reporting errors $(t(94)=1.58, p=.12)$ had all decreased to near pre-intervention scores.

\section{DISCUSSION}

This is the first study to evaluate the effectiveness of a face-to-face intervention designed to improve the current patient safety attitudes of intern pharmacists. Specifically, this study examined the short- and medium-term effect of this intervention in changing interns' attitudes on four factors: addressing errors, questioning senior health care professionals' behaviors, blaming individuals involved in errors, and reporting errors. There was 


\section{American Journal of Pharmaceutical Education 2017; 81 (1) Article 5.}

Table 3. Intern Pharmacists' Attitudinal Factor-based Mean Scores Before and After the Program

\begin{tabular}{|c|c|c|c|c|c|c|}
\hline Factor & $\begin{array}{c}\text { Immediately Prior } \\
\text { to Program (T1), } \\
\text { Mean (SD) }\end{array}$ & $\begin{array}{c}\text { Immediately } \\
\text { After Program (T2), } \\
\text { Mean (SD) }\end{array}$ & $\begin{array}{c}\text { Three Months } \\
\text { After Program (T3), } \\
\text { Mean (SD) }\end{array}$ & $P$-value ${ }^{\text {b }}$ & $\begin{array}{c}\text { Immediate } \\
\text { Effect } \\
p \text {-Value }\end{array}$ & $\begin{array}{c}\text { Long- term } \\
\text { Effect } \\
p \text {-Value }\end{array}$ \\
\hline $\begin{array}{l}\text { 1. Addressing } \\
\text { errors }\end{array}$ & $12.1(1.4)$ & $12.6(1.3)$ & $12.2(1.3)$ & $<0.001$ & $<0.001$ & 0.360 \\
\hline $\begin{array}{l}\text { 2. Questioning } \\
\text { behaviors }\end{array}$ & $7.0(0.9)$ & $7.4(0.9)$ & $7.2(0.9)$ & 0.002 & 0.001 & 0.053 \\
\hline $\begin{array}{l}\text { 3. Blaming the } \\
\text { individual }\end{array}$ & $6.2(1.3)$ & $6.8(1.3)$ & $6.6(1.3)$ & $<0.001$ & $<0.001$ & 0.002 \\
\hline $\begin{array}{l}\text { 4. Reporting } \\
\text { errors }\end{array}$ & $6.1(0.8)$ & $6.5(0.7)$ & $6.3(0.8)$ & $<0.001$ & $<0.001$ & 0.117 \\
\hline
\end{tabular}

a significant improvement in all of the four factors immediately after the intervention. However, only one of the four factors continued to show a significant improvement after three months.

The only factor to have maintained improvement when compared to baseline was interns' attitudes toward blaming individuals involved in errors. This factor consisted of four items. Three of these items are related to a concept defined by reason as the "individual approach to error," "3 specifically evaluating the use of disciplinary action, believing that competent health care professionals do not make errors and that effective responses to errors should focus primarily on the health care professional involved. In addition, this factor also consisted of an item examining interns' attitudes towards "sweeping errors under the carpet," where the causes of the incident are not acknowledged. Since the publication of the seminal reports 15 years ago, health care organizations have pushed to change the manner in which health care professionals deal with errors, from taking an individual approach to taking a systems approach. ${ }^{3,4}$ The results of this study in pharmacy interns mirror the findings of other studies conducted in other health care disciplines that have highlighted that education can improve the manner in which early-career health care professionals perceive errors and patient safety issues. ${ }^{5,6,8}$ In addition, the culture of covering up errors, a problem identified in older pharmacists, ${ }^{27}$ has been shown to change through education, as also seen in interventions for medical students and residents. ${ }^{21,28}$

Even though improvement in attitudes towards blaming individuals was sustained, factor scores relating to interns' attitudes towards addressing errors, questioning behaviors, and reporting errors did not show any significant improvement from baseline scores three months after the intervention. This result is contrary to those seen in other studies of students and other early-career health care professionals where attitudinal improvements in these three areas were sustained. ${ }^{21,29,30}$ It is therefore important to consider the potential influences on these three factors.

The factor relating to addressing errors consisted of five items that related to internalizing errors and learning from error; the factor related to questioning behaviors consisted of two items relating to questioning the behaviors of a registered pharmacist and a prescriber; and the factor related to reporting errors consisted of three items investigating interns' attitudes towards reporting errors with regards to patient harm. All three factors represent interns' attitudes towards actioning an error or a patient safety issue they may face in practice. Conversely, the factor relating to blaming individuals is centered on the individual intern's perspective. Considering that the interns have been working full time between the last two survey time points, their experiences in their workplace are expected to have a considerable effect in negatively influencing patient safety attitudes, which maps to professional socialization theory. ${ }^{15}$ Schein's organizational culture theory suggests that the safety attitudes and behaviors of managers will form the safety behaviors of the individual workers. ${ }^{31}$ In addition, Ashcroft has identified that a pharmacy's ownership and staffing are key to its safety culture. ${ }^{32}$ After triangulating the results of this study with these theories, it can be concluded that it is ultimately the workplace culture and those in senior or managerial positions that are having the greatest impact on interns' attitudes and responses to patient safety issues. Furthermore, it was hypothesized that there would be a difference between hospital and community interns' attitudes to safety, mainly due to many hospitals engaging in patient safety initiatives and that community pharmacy is only starting to be included in patient safety frameworks. In this study, however, there were no significant differences between the attitudes of interns based in 


\section{American Journal of Pharmaceutical Education 2017; 81 (1) Article 5.}

hospitals or in the community. The issues identified are therefore relevant across all pharmacy settings.

It has been suggested that interns have the ability to be change agents in their own practice settings, ${ }^{33}$ which has great implications for advancing patient safety. This study has shown that patient-safety specific education is an important element in improving intern pharmacists' safety attitudes, however, a single face-to-face education program was not sufficient in sustaining interns' safety attitudes. Studies in other industries have overcome this issue by providing repeated training sessions. ${ }^{34}$ Studies have also shown that there is a discord between interns' perceived practice roles and their actual practice roles. ${ }^{12}$ This was also evident in the verbal feedback received by the pharmacists delivering the patient safety workshops. The use of mentoring in intern programs may be a solution to this issue, and has been demonstrated to improve practice behaviors and attitudes in other health disciplines. ${ }^{35}$ Mentoring can provide interns with an opportunity to discuss problems they encounter and be guided in targeted management strategies to their specific issues. ${ }^{36}$ However, future research is required to evaluate a combination of face-to-face education and a mentoring program for interns.

This study had a number of strengths. This is the first study to evaluate an intervention to improve patient safety attitudes among pharmacist interns. The process of evaluation consisted of one of the most used patient safety curriculum survey tools, which has been recently validated in pharmacy students, ${ }^{22}$ and used a rigorous method to evaluate the intervention: EFA and ANOVA combined with post-hoc tests to understand the effect of the intervention in changing patient safety attitudes.

Despite these strengths, there are a few limitations. The study's sample size was towards the lower acceptable bounds of conducting both EFA and ANOVA. While this may limit the generalizability of the results, the demographics of the sample were similar to those of other studies of intern pharmacist populations, ${ }^{12,13}$ indicating that results may be generalizable to intern pharmacists in other states of Australia. In addition, one of the attitudinal factors (questioning behaviors) only consisted of two items, which is less than the recommended three items. ${ }^{23}$ This is likely due to the use of a short survey tool, which was designed to encourage participation and completion by interns. However, these two items also had high factor loadings and the factor showed high internal reliability, suggesting that the two items on their own sufficiently explained the factor.

\section{CONCLUSION}

The intern year marks the transition from pharmacy student to professional. This period has the greatest impact on the professional socialization of early-career pharmacists and the acquisition of attitudes and values that govern their future practice. ${ }^{15}$ Overall, this study has identified that a single face-to-face intervention is effective in having an immediate impact in improving intern pharmacists' attitudes to patient safety. Although the personal patient safety attitudes of interns may remain positive, such as towards blaming individuals, their attitudes towards actioning patient safety issues are likely to be affected by other factors and as a result, do not sustain improvement long term. Professional socialization theory suggests that these factors may most likely be related to poor work environments. It is therefore necessary that interns be provided with additional mechanisms such as follow-up face-to-face sessions and positive role models and mentors through their intern training programs to enhance attitudinal sustainability and enable generational change.

\section{ACKNOWLEDGMENTS}

The authors would like to thank Dr. Erica Sainsbury for her assistance in the development and running of the study. Additional, the authors thank the faculty of pharmacy for supporting this project and the intern pharmacists who participated in this study.

\section{REFERENCES}

1. Kohn LT, Corrigan J, Donaldson MS. To Err Is Human: Building a Safer Health System. Washington, DC: Institute of Medicine; 2000 .

2. Department of Health. An organisation with a memory. London, UK: Department of Health; 2000.

3. Reason J. Human error: models and management. BMJ. 2000;320 (7237):768-770.

4. Mitchell I, Schuster A, Smith K, Pronovost P, Wu A. Patient safety reporting: a qualitative study of thoughts and perceptions of experts 15 years after 'To Err is Human.' BMJ Qual Saf. 2015. doi:10.1136/bmjqs-2015-004405.

5. Nie Y, Li L, Duan Y, et al. Patient safety education for undergraduate medical students: a systematic review. BMC Med Educ. 2011;11(1):33.

6. Wong BM, Etchells EE, Kuper A, Levinson W, Shojania KG. Teaching quality improvement and patient safety to trainees: a systematic review. Acad Med. 2010;85(9):1425-1439

7. Teigland CL, Blasiak RC, Wilson LA, Hines RE, Meyerhoff KL, Viera AJ. Patient safety and quality improvement education: a crosssectional study of medical students' preferences and attitudes. $B M C$ Med Educ. 2013;13:16.

8. Kiersma ME, Plake KS, Darbishire PL. Patient safety instruction in US health professions education. Am J Pharm Educ. 2011;75(8): Article 162.

9. World Health Organization. WHO Patient Safety Curriculum: Multi-professional Edition. Geneva, Switzerland: WHO Press; 2011.

10. Kiersma ME, Darbishire PL, Plake KS, Oswald C, Walters BM. Laboratory session to improve first-year pharmacy students'

knowledge and confidence concerning the prevention of medication errors. Am J Pharm Educ. 2009;73(6):Article 99.

11. Walpola RL, Fois RA, McLachlan AJ, Chen TF. Evaluating the effectiveness of a peer led education intervention to improve the 


\section{American Journal of Pharmaceutical Education 2017; 81 (1) Article 5.}

patient safety attitudes of junior pharmacy students: a cross-sectional study using a latent growth curve modelling approach. BMJ Open. 2015;5(12):e010045.

12. Mak VSL, March G, Clark A, Gilbert AL. Do South Australian pharmacy interns have the educational and behavioural precursors to meet the objectives of Australia's health care reform agenda? Int $J$ Pharm Pract. 2014;22(5):366-372.

13. Mak VSL, March G, Clark A, Gilbert AL. Australian intern pharmacists' perceived preparedness for practice, and their expectations and experiences of the internship year and future career intentions. Integr Pharm Res Pract. 2013;2:25-34.

14. Pharmacy Board of Australia. Supervised practice arrangements registration standard. Melbourne, Australia; 2010.

15. Fitzpatrick JM, While AE, Roberts JD. Key influences on the professional socialisation and practice of students undertaking different preregistration nurse education programmes in the United Kingdom. Int J Nurs Stud. 1996;33(5):506-518.

16. Ajjawi R, Higgs J. Learning to reason: a journey of professional socialisation. Adv Health Sci Educ Theory Pract. 2008;13(2):133150 .

17. Nimmo CM, Holland RW. Transitions in pharmacy practice, part 4: can a leopard change its spots? Am J Health Syst Pharm. 1999;56 (23):2458-2462.

18. Howkins EJ, Ewens A. How students experience professional socialisation. Int J Nurs Stud. 1999;36(1):41-49.

19. Ahmed M, Arora S, Baker P, Hayden J, Vincent C, Sevdalis N. Building capacity and capability for patient safety education: a trainthe-trainers programme for senior doctors. BMJ Qual Saf. 2013;22 (8):618-625.

20. Ahmed M, Arora S, Baker P, Vincent C, Sevdalis N. Case-based learning for patient safety: the lessons learnt program for UK junior doctors. World J Surg. 2012;36(5):956-958.

21. Madigosky WS, Headrick LA, Nelson K, Cox KR, Anderson T. Changing and sustaining medical students' knowledge, skills, and attitudes about patient safety and medical fallibility. Acad Med. 2006;81(1):94-101.

22. Walpola RL, Fois RA, Carter SR, McLachlan AJ, Chen TF. Validation of a survey tool to assess the patient safety attitudes of pharmacy students. BMJ Open. 2015;5(9):e008442.
23. Tabachnick BG, Fidell LS. Using Multivariate Statistics. 6th ed. New Jersey, NJ Pearson; 2013.

24. Comrey AL, Lee HB. A First Course in Factor Analysis. 2nd ed. Hillsdale, NJ: Lawrence Erlbaum Associates; 1992.

25. DiStefano C, Zhu M, Mindrila D. Understanding and using factor scores: considerations for the applied researcher. Pract Assess Res Eval. 2009;14(20):1-11.

26. Norman G. Likert scales, levels of measurement and the "laws" of statistics. Adv Health Sci Educ Theory Pract. 2010;15(5):625-632. 27. Lalor DJ, Chen TF, Walpola R, George RA, Ashcroft DM, Fois RA. An exploration of Australian hospital pharmacists' attitudes to patient safety. Int J Pharm Pract. 2015;23(1):67-76.

28. Kerfoot BP, Conlin PR, Travison T, McMahon GT. Patient safety knowledge and its determinants in medical trainees. $J$ Gen Intern Med. 2007;22(8):1150-1154.

29. Nishisaki A, Hales R, Biagas K, et al. A multi-institutional highfidelity simulation "boot camp" orientation and training program for first year pediatric critical care fellows. Pediatr Crit Care Med. 2009;10(2):157-162.

30. Cox KR, Scott SD, Hall LW, Aud MA, Headrick LA, Madsen R. Uncovering differences among health professions trainees exposed to an interprofessional patient safety curriculum. Qual Manag Health Care. 2009;18(3):182-193.

31. Schein EH. Organizational Culture and Leadership. Vol. 2. San Francisco, CA: John Wiley \& Sons; 2010.

32. Ashcroft DM, Morecroft C, Parker D, Noyce PR. Safety culture assessment in community pharmacy: development, face validity, and feasibility of the Manchester Patient Safety Assessment Framework. Qual Saf Health Care. 2005;14(6):417-421.

33. Schneider CR, Everett AW, Geelhoed E, et al. Intern pharmacists as change agents to improve the practice of nonprescription medication supply: provision of Salbutamol to patients with asthma. Ann Pharmacother. 2010;44(7-8):1319-1326.

34. Satava RM. Historical review of surgical simulation - a personal perspective. World J Surg. 2008;32(2):141-148.

35. Sambunjak D, Straus SE, Marušić A. Mentoring in academic medicine: a systematic review. JAMA. 2006;296(9):1103-1115. 36. Colvin JW. Peer tutoring and social dynamics in higher education. Mentoring \& Tutoring. 2007;15(2):165-181. 